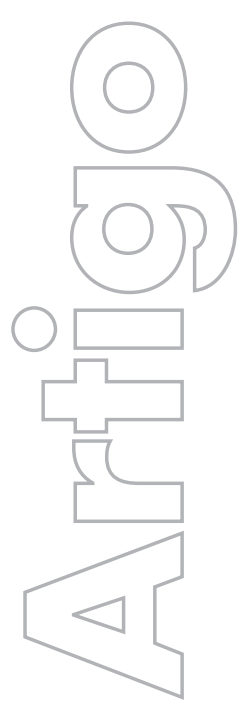

revista

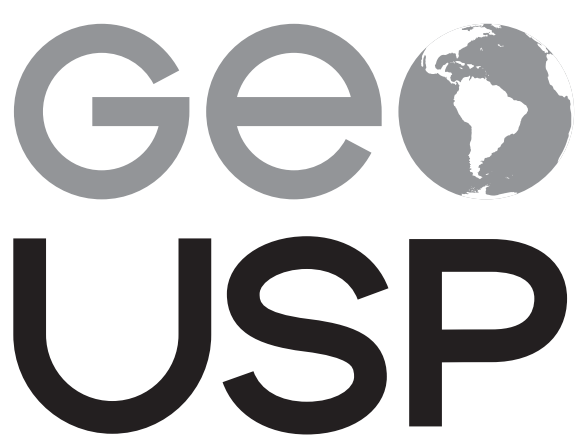

espaço e tempo

Volume $20 \cdot n^{\circ} 2(2016)$

ISSN 2179-0892
A certificação do latifúndio: considerações acerca do registro Torrens como blindagem da propriedade privada no caso das terras concentradas pelo Projeto Jari

Maria Luiza Camargo USP

p. $330-348$

Como citar este artigo:

CAMARGO, M. M. A certificação do latifúndio: considerações acerca do registro Torrens como blindagem da propriedade privada no caso das terras concentradas pelo Projeto Jari. Geousp - Espaço e Tempo (Online), v. 20, n. 2, p. 330-348, mês. 2016. ISSN 2179-0892.

Disponível em: <http://www.revistas.usp.br/geousp/issue/ view/6465>. doi: http://dx.doi.org/10.11606/issn.2179-0892. geousp.2014.84539.

\section{(c) $(1) \Theta$}

Este artigo está licenciado sob a Creative Commons Attribution 4.0 License. 


\title{
A certificação do latifúndio: considerações acerca do registro Torrens como blindagem da propriedade privada no caso das terras concentradas pelo Projeto Jari
}

\section{Resumo}

$\bigcirc$ latifúndio constituído pelas terras do controverso Projeto Jari na divisa dos estados do Pará e do Amapá, na Amazônia brasileira, é composto pelo pretenso remembramento de mais de uma centena de imóveis. A legitimidade dessas terras é questionada em diversas e emaranhadas demandas judiciais. Pretende-se aqui dar um panorama da situação fundiária dessa área avaliando a apropriação ilegal de terras públicas, sobretudo por meio de registros Torrens, uma modalidade de registro imobiliário que garante uma blindagem especial à propriedade.

Palavras-chave: Latifúndio. Projeto Jari. Registro Torrens. Grilagem. Amazônia.

The landed estate certification: considerations about the Torrens registry as a way of shielding private property in the case of land concentrated by the Jari Project

\begin{abstract}
The landed estate of the Jari Project, which straddles the border between the Brazilian Amazonian states of Para and Amapa, is allegedly composed of the combination of more than one hundred areas. The legitimacy of these lands is questioned in various entangled lawsuits. This article presents an overview of these lands' situation, evaluating the illegal appropriation of public land, especially through the use of Torrens registry, a real estate registration method that guarantees a special shield to property.
\end{abstract}

Keywords: Landed estate. Jari Project. Torrens registry. Landgrabbing. Amazonia.

Este artigo é um dos resultados da pesquisa de mestrado orientada pelo prof. dr. Ariovaldo U. de Oliveira no Programa de Pós-graduação em Geografia Humana da Universidade de São Paulo (USP), com bolsa da Coordenação de Aperfeiçoamento de Pessoal de Nível Superior (Capes) e apoio do Programa Procad-Casadinho CNPq/Capes. 


\section{Introdução}

Na década de 1970, o bilionário empresário estadunidense Daniel K. Ludwig chama a atenção internacional para a Amazônia brasileira com a implementação do ousado e polêmico Projeto Jari, com o qual pretendia se tornar o maior produtor mundial de celulose. ${ }^{2}$ Instalado no vale do rio Jari, marco natural da divisa dos estados do Pará e do Amapá, o projeto fazia de Ludwig proprietário de um latifúndio de mais de 2 milhões de hectares.

Após receber centenas de milhões em incentivos na onda dos grandes projetos do governo militar para a Amazônia, e acumular escândalos e prejuízos, em 1982, o Projeto é assumido por um grupo de empresas nacionais e, em 2000, passa para o comando do Grupo Orsa, um conglomerado paulista do setor de papel e celulose. $\bigcirc$ Grupo Orsa é conhecido hoje como exemplo pioneiro de "empresa verde" e já recebeu muitos prêmios como reconhecimento de sua responsabilidade social e ambiental. Na Amazônia, porém, ele opera num dos maiores latifúndios do mundo, em meio a conflitos com posseiros e envolvido em processos judiciais que apuram grilagem de terras e irregularidades do plano de manejo florestal em atividade. ${ }^{3}$

Na verdade, a espantosa concentração fundiária não teria sido feito de Ludwig, mas de José Júlio de Andrade, um cearense de Sobral, chegado ao vale por volta de 1882 (Lins, 1991) e que, em pouco mais de uma década, firmou-se como um dos mais ricos e influentes homens da região. Foi Andrade que - de modo lídimo ou não - foi acumulando imóveis supostamente contíguos até formar o latifúndio que, após passar por um grupo de empresários portugueses e pelo próprio Ludwig, chegaria, no início da década de 1980, às mãos de empresários brasileiros e, posteriormente, do Grupo Orsa.

A legitimidade dos títulos que compõem o latifúndio é questionada em imbricadas contendas judiciais ainda inconclusas - nos debruçamos sobre ela em nossa pesquisa de mestrado (Camargo, 2015). Em resumo, podemos afirmar que há ilegalidades nos documentos de propriedade apresentados pela Jari Celulose, Papel e Embalagens S/A (a partir daqui, referida apenas como Jari), empresa que compõe o Grupo Orsa e que atualmente reivindica a propriedade do latifúndio. Há, portanto, apropriação de terras públicas. Talvez o caso mais evidente seja o da Fazenda Saracura, cuja área especificada no título de posse é de 2,64 milhões de hectares. Além de exceder

2 Há bibliografia relativamente farta sobre o Projeto Jari. Entre os mais críticos, estão Sautchuk, Carvalho e Gusmão (1981), Garrido (1980), Pinto (1986) e Silveira (1980), que tratam especificamente do Projeto, e Oliveira (1995), lanni (1986) e Morel (1989), que discutem-no num contexto mais amplo.

3 Mais recentemente, em 7 de julho de 2015, a Jari Florestal foi multada pelo Ibama em R \$ 5,989 milhões por crime ambiental e teve suas atividades suspensas, pondo em xeque o título de empresa ambientalmente responsável que lhe é atribuído (Gl Santarém, 2015).

4 ○ "título de posse" é uma peculiaridade da legislação estadual paraense. Com o fim do Império, a Constituição da República, de 24 de fevereiro de 1891, transferiu para o domínio estadual as terras devolutas. Assim, a gestão das terras paraenses (excluídas aquelas de jurisdição federal, a saber, faixa de fronteira e faixa de marinha) passou a ser regida pelo Decreto Estadual n. 410, de 8 de outubro de 1891, que "regula a alienação das terras devolutas situadas nos limites do estado do Pará, e dá regras para a revalidação de sesmarias e outras concessões do governo e para a legitimação das posses mansas e pacíficas". No geral, tal regulamento adota "a mesma sistemática da lei de terras nacional" (Treccani, 2001, p. 99). A grande novidade desse decreto, discutida por todos os agraristas, é o instituto jurídico do "título de posse". Em resumo, tal título não configurava propriedade, pois, para tanto, deveria passar por um processo de legitimação. De acordo com o Decreto n. 410, os registros de terras deveriam ser feitos em dois livros: "um no qual eram registradas as propriedades e outro no qual seriam registrados os títulos sujeitos a legitimação e reavaliações", como os títulos de posse (Treccani, 2001, p. 103). Com poucas cartas de sesmarias (Treccani, 2001), os títulos de posse foram o instrumento mais usado para a destinação de terras públicas no Pará no início da República. E uma quantidade enorme desses títulos sem legitimação permanecem muitas vezes registrados como se propriedade fossem, alimentando a grilagem no estado. 
muito o limite legal para a emissão desse tipo de título (máximo de uma légua por uma légua, ou 4.356 ha), essa extensão é tão absurda que, se a somarmos às outras áreas que a Jari reivindica e considerarmos os rios Paru, Jari e Amazonas seus limites naturais, ela não caberia no continente, atravessaria o Suriname e avançaria quilômetros pelas águas do Caribe.

Neste texto, porém, tratamos dos registros Torrens pretendidos pela Jari, em especial o imóvel denominado Santo Antônio da Cachoeira - mais especificamente, sua porção paraense. Além de também apresentar uma extensão considerável - mais de 422 mil hectares, se somadas as áreas incidentes no Pará e no Amapá -, teria, ainda, uma peculiar situação fundiária ao contar com um suposto registro Torrens. Pela análise da documentação do imóvel Santo Antônio da Cachoeira, à luz do histórico de composição do latifúndio do Projeto Jari, este artigo busca mostrar como esse tipo de registro pode ter concorrido para blindar a propriedade privada pretendida atualmente pela Jari, mesmo com legitimidade questionável.

\section{A composição do latifúndio}

Atualmente, o Grupo Orsa se diz dono de 916.602 ha no Pará, no município de Almeirim, cadastrados como um único imóvel, ${ }^{5}$ a gleba Jari ${ }^{6}$ (Mapa 1), de acordo com o sistema declaratório do Cadastro Ambiental Rural (CAR), ${ }^{7}$ em nome da Jari Celulose, Papel e Emba-

5 Os agraristas são unânimes ao afirmar que a definição de imóvel rural no Direito Civil não é a mesma que lhe confere - Direito Agrário. A partir da óptica agrária, "a destinação que se dá ao imóvel ou a atividade nele exercida configura o principal elemento caracterizador do imóvel rural" (Incra, 2011, p. 28); assim, se o uso for caracterizado como rural, de imóvel rural se trata, mesmo inserido em perímetro urbano. Segundo o Estatuto da Terra (Lei n. 4.504, de 30 de novembro de 1964, art. 4., inciso I), imóvel rural é "o prédio rústico, de área contínua, qualquer que seja a sua localização, que se destina à exploração extrativa agrícola, pecuária ou agro-industrial [...]” (grifo nosso). Assim, um "imóvel rural” pode ser formado por várias "propriedades rurais" (estas relacionadas à matrícula única), desde que haja "unidade de exploração econômica voltada ao desenvolvimento de atividades agrárias" (Chacpe, [2012], p. 8). Segundo Chacpe, a Procuradoria Especializada do Incra considera que "a expressão 'área contínua' é entendida pela doutrina como sendo a continuidade do empreendimento, da utilidade econômica extraída do bem, e não do aspecto puramente físico, material, de indivisibilidade do bem" (Chacpe, [2012], p. 9). Para o Incra (2011, p. 29), "[...] a realidade existente em campo se contrapõe à noção dada pelo Direito Civil, de que o imóvel rural estaria relacionado à propriedade devidamente delimitada e registrada no Cartório de Registro de Imóveis. Vale dizer que o conceito de imóvel rural é diverso e distancia-se da noção de propriedade rural". Essa definição pretendeu impedir que se mascarassem latifúndios pelo parcelamento da terra em várias matrículas. Assim, podemos dizer que a área reivindicada pela Jari é um único imóvel rural composto por diversas matrículas.

6 De acordo com o Cadastro Ambiental Rural n. 66.149, provisório, com data de 2 fevereiro de 2012.

7 CAR foi criado pela Lei 12.651, de 25 de maio de 2012, no âmbito do Sistema Nacional de Informação sobre Meio Ambiente - Sinima, com o objetivo de, finalmente, avançar a regularização ambiental de imóveis rurais (http://www.car. gov.br/\#/sobre), mas vem sofrendo duras críticas, tanto a respeito de sua efetividade no âmbito ambiental quanto na sua relação com questões fundiárias. Grande parte das críticas decorrem do fato de ser um cadastro declaratório, com pouca ou precária ação prática no sentido de se verificarem em campo as informações prestadas; com apenas a etapa declaratória, já é possível o acesso às vantagens oferecias em troca da adesão ao CAR, como crédito agrícola e suspensão de multas ambientais (Araújo, 2014a, 2014b). Quanto às questões fundiárias, Eliane Cristina Pinto Moreira (2014), promotora do Minstério Público Estadual do Pará, alerta para o fato de o CAR ser um instrumento criado na área ambiental que não dialoga com os dados fundiários. Para a promotora, sua Instrução Normativa (MMA, 2014) está "completamente em descompasso com o Estatuto da Terra”. Alguns dos problemas enumerados por ela são: (1) a definição de imóvel rural utilizada aceita que não haja nenhum tipo de uso da área a ser cadastrada, o que seria contrário à ideia de posse agrária ou de posse agroecológica; (2) não há nenhum limite para o tamanho das propriedades, o que desampara a erradicação do latifúndio tal como estabelecida no Estatuto da Terra (Brasil, 1964); (3) a exigência de comprovação da posse ou propriedade não é cumprida, sendo aceitos os mais diversos tipos de documentos e declarações, gerando conflitos e sobreposições; (4) a ideia de facilitar a regularização fundiária de quem tem CAR põe de lado a prioridade de assentamento de familias de trabalhadores rurais, tal como estabelece a Constituição do Estado do Pará; (5) segundo o novo código florestal, o registro de reserva legal no CAR desobrigaria a averbação no cartório de registro de imóveis da área de reserva legal, o que facilitaria sua redefinição ao longo do tempo, levando a instabilidade e incerteza da preservação. 
lagens S/A. Porém, se ao órgão ambiental a situação do imóvel parece estabelecida e regular a partir do que declara sua suposta proprietária, o mesmo não se aplica a sua situação fundiária. A esse respeito, a área reivindicada pela Jari é composta de mais de uma centena de matrículas que tiveram origem nos mais diferentes tipos de documentos, que vão desde propriedades registradas a aforamentos, passando por títulos de posse e até os referidos registros Torrens. Além disso, entre esses diferentes tipos há os regularizados, os legitimáveis e os que apresentam vícios que põem em dúvida sua legalidade.

\section{Mapa 1 - Porção paraense do Projeto Jari segundo declaração do Grupo}

\section{Orsa ao Cadastro Ambiental Rural}

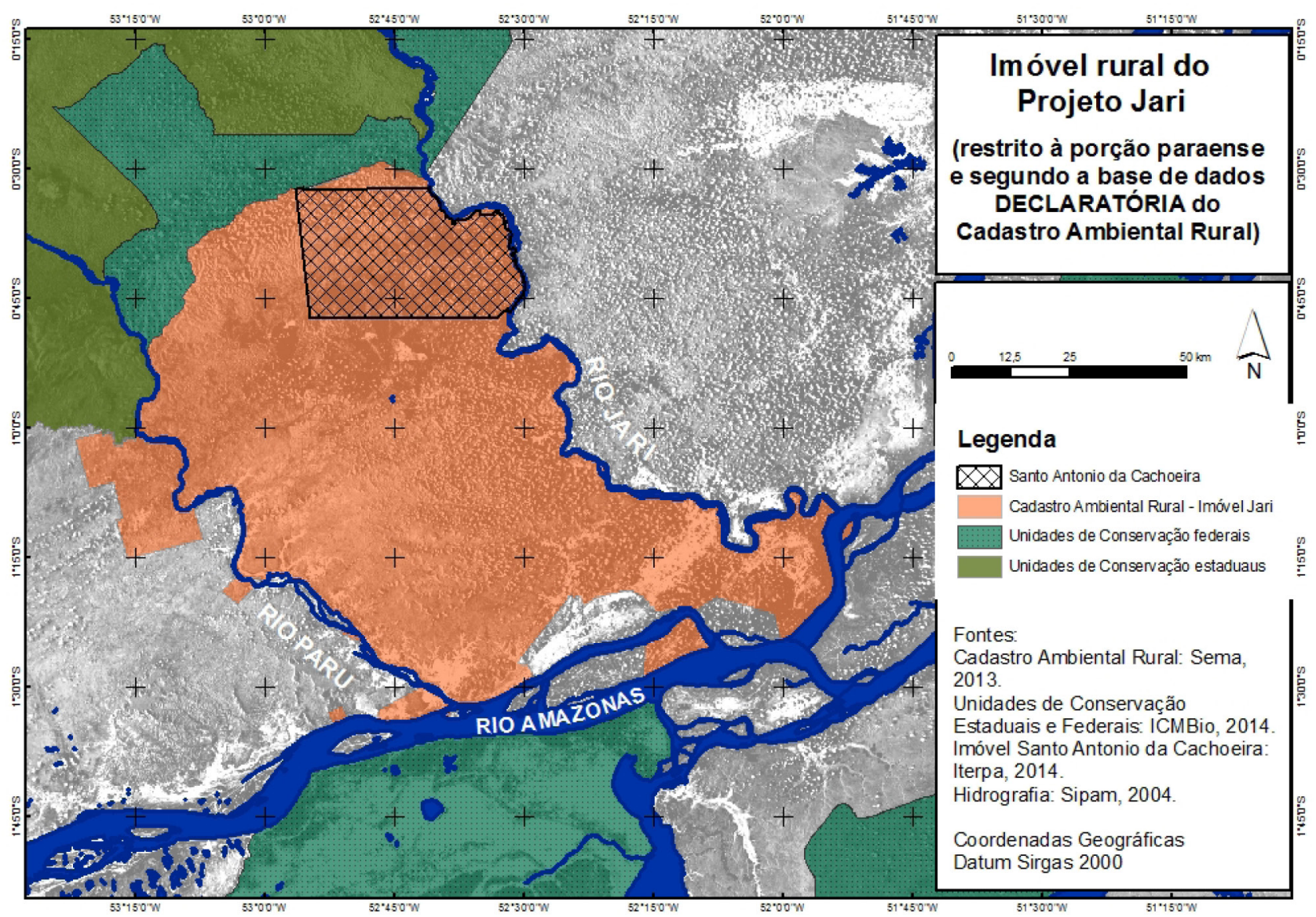

Qual seria, de fato, o tamanho da área da Jari é outra pergunta que recebeu diferentes respostas ao longo do tempo.

Ao vender todas as suas terras no vale do Jari, em 1948, José Júlio de Andrade não diz o tamanho total da área, mas, antes de efetivar a venda, pediu autorização ao governo do Pará para transferir os títulos de posse para a Empresa Jari Ltda. (Processo n. 0577/1948 - Iterpa) e, em setembro de 1948, um engenheiro do Departamento de Obras, Terras e Vias do governo estadual, após análise da documentação apresentada por José Júlio, chegou à extensão de 4.338.357,4288 ha (Processo n. 0577/48 - Iterpa, p. 11), distribuídos entre o estado do Pará e o Território Federal do Amapá. ${ }^{8}$

8 À época, o território federal do Amapá já havia sido administrativamente separado do estado do Pará, o que ocorreu em 1943. 
Em 1969, na época da implantação do Projeto Jari, em um pedido de incentivos fiscais à Sudam, a empresa se declarou proprietária de 3.654 .491 ha, sendo 579.013 ha no município de Mazagão, no Amapá, e 3.075.478 ha em Almeirim (Oliveira, 1995, p. 22 et seq.). No cadastro do Incra, em 1977, porém, constava a declaração de 1.006.261,9 ha em nome da Jari (Sautchuk; Carvalho; Gusmão, 1981, p. 62). Acerca da "elasticidade" das dimensões desse imóvel, Oliveira (1995, p. 22) ainda afirma que "o que se sabe é que o projeto em si envolve em torno de 1.632.000 ha".

Em 21 de julho de 1997, Ronaldo Barata, então presidente do Iterpa, afirma que inicialmente a empresa considerava propriedade sua cerca de 3,7 milhões de hectares, nos estados do Pará e do Amapá, e que essa extensão, porém, "veio a ser posteriormente retificada, pela própria empresa, para 1,6 milhões de hectares, compreendidas as áreas tidas como propriedade plena, os registros de posses sujeitos a legitimação e, por último, os imóveis aforados pelo Estado".?

De acordo com o levantamento sistematizado por Carlos Lorena (Silva, J., 1986, p. 28 et seq.), constavam, em 1980, 2.918.892 ha declarados em nome da Jari no cadastro do Incra. Em 1984, com a denominação Cia. Florestal Monte Dourado, a mesma empresa declarou ao órgão fundiário possuir 1.682.227 ha (Silva, J., 1986).

Na verdade, em 1979, Avertano Rocha, advogado da Jari, ${ }^{10}$ já havia admitido a incongruência desses números em depoimento à Comissão de Segurança Nacional da Câmara dos Deputados: "Temos efetivamente títulos de posse que ultrapassam a 3.800.000 ha", afirmou. Contudo, prossegue, "fazendo um levantamento da área, verificamos que, na realidade, esses títulos não podem ultrapassar [...] 1.600.000 ha, inclusive pela própria localização em que nos encontramos" (apud Garrido Filha, 1980, p. 14). O motivo dessa impossibilidade seria principalmente a Fazenda Saracura: "sabemos que, fisicamente, é impossível se colocar a Fazenda Saracura, com 2.400.000 ha, na região onde nos encontramos" (apud Garrido Filha, 1980, p. 13).

Não há, portanto, quem discorde da existência de discrepâncias e irregularidades na documentação das terras reivindicadas pela empresa.

Os títulos apresentados pela Jari que pudemos encontrar no Iterpa somam um total de 3.147.541,1438 ha" e dizem respeito apenas à parte paraense do latifúndio, uma área muito maior que a declarada pela empresa no CAR (916.602 ha). Quanto ao tipo, esses documentos são:

- Títulos que podem atribuir propriedade: 41 títulos de legitimação de posse (somando 68.817,6462 ha); 2 títulos definitivos de venda de terras (10.739,69ha); 6 imóveis com supostos registros Torrens (um deles, Santo Antônio da Cachoeira, com título de propriedade) (147.309,5406 ha).

- Títulos que não atribuem propriedade: 19 aforamentos (78.932,667 ha); 33 títulos de posse (2.839.563,6 ha) e 1 registro paroquial (2.178 ha).

9 Ofício n. 0316/97 do gabinete da presidência do Iterpa dirigido ao diretor de Desenvolvimento Regional do BNDES, que está entre as páginas iniciais do Processo n. 05562/76 (Iterpa), sem numeração.

10 Treccani (2001, p. 238) chama a atenção para o fato de Avertano Rocha também ter defendido Cecilio do Rego Almeida no famoso processo movido pelo Iterpa por grilagem de terras em Altamira. Sobre o caso, ver, entre outros, Lúcio Flávio Pinto (2013).

11 Vale notar que, em 30 de julho de 1997, a Jari vendeu parte dos imóveis Campos Saracura, Arumanduba, Santa Maria do Arumanduba, Santana, São Miguel e Pedreira (na área da foz do rio Arraiolos) para a D. D. Uliana Administração Industrial Ltda., constituindo a matrícula n. 4.532, fls. 33, livro 2-R do Registro de Imóveis de Monte Alegre, com uma área total de 22.353 ha. 
Quanto à observância da legislação cabível, podemos dividi-los em:

- Títulos sem irregularidades: 38 títulos de propriedade (42.386,633 ha); 26 títulos de posse (55.515,6 ha); 16 aforamentos (58.269,2911 ha). Um total de 156.171,5241 ha.

- Títulos com alguma irregularidade: 6 imóveis com supostas matrículas Torrens (147.309,5406 ha); 1 título de posse caduco (100 ha); além dos seguintes imóveis com áreas maiores que o permitido pela legislação da época: 5 títulos de propriedade (37.170,7032 ha); 3 aforamentos (20.663,3759 ha); 6 títulos de posse (2.786.126 ha). Um total de 2.991.369,6197 ha (Camargo, 2015).

Ou seja, de apenas 5\% da área constante nos títulos, pode-se dizer que estão em situação regular.

Além da questão de os imóveis que compõem o latifúndio serem ou não títulos legítimos ou passíveis de ser regularizados, há ainda a incerteza sobre o lugar onde tais títulos incidiriam, se de fato onde os desenha a empresa ou não.

Para qualquer imóvel ser considerado propriedade privada, ele precisa, antes, ser destacado do patrimônio público, isto é, estar associado a um documento em que se afirme que, por dada forma, ele deixou de ser terra pública para integrar o patrimônio de alguém. Nesse processo de destacamento de terras do patrimônio público, seja federal, estadual ou municipal, precisam estar claras suas dimensões e sua localização. As terras hoje pretendidas pela Jari deveriam ter passado (como algumas porções efetivamente o fizeram) por processo de medição e demarcação ainda no fim do século XIX e início do XX, constituindo, para cada um dos imóveis, os então chamados "autos de medição e demarcação". Nesses autos, haveria a descrição de limites a partir de coordenadas geográficas acompanhada por plantas ou, ao menos, croquis mais precisos. Antes dos autos de medição e demarcação, a pretensão de um particular de adquirir terras públicas (que, frise-se, por si só não configurava o destacamento do imóvel do patrimônio púbico) aceitava que o imóvel em questão fosse descrito a partir de marcos naturais ou simplesmente citando os confrontantes. Os autos de medição e demarcação constituem, então, processo indispensável para que determinada área seja reconhecida como propriedade.

Tais autos referentes aos imóveis no município de Almeirim, instaurados há mais de cem anos, estão em geral bastante deteriorados, e a maioria não tem mais as plantas (ou os croquis) legíveis. Mesmo nos casos em que elas se encontram em condições razoáveis, nem sempre é possível relacionar o imóvel ali representado com áreas hoje reivindicadas pela Jari, isso por conta da significativa ocorrência de posses homônimas e, também, das que tiveram seus nomes trocados ao longo da cadeia dominial, muitas vezes em razão de desmembramentos ou remembramentos. Em muitos casos a própria Jari não logrou, até hoje, reconstituir a cadeia dominial que liga essas posses aos imóveis que requer. Para ter suas áreas legitimadas ou reconhecidas, a empresa deve, portanto, além de comprovar a cadeia dominial que leva o imóvel até ela, ${ }^{12}$ proceder ao mapeamento da área.

12 Para os casos de legitimação de posse, a exigência para comprovação da cadeia sucessória diminuiu para os últimos 20 anos, contados a partir do pedido de legitimação. Isso se deu com a Lei n. 4.884, de 11 de dezembro de 1979. Essa alteração na lei facilitaria muito as pretensões da Jari, uma vez que a quase totalidade das terras que reivindica foram compradas em 1948 pela Empresa Jari Ltda., da qual a Jari Celulose, Papel e Embalagens S/A é sucessora. Assim, não haveria necessidade de apresentar a cadeia dominial, mas apenas as alterações societárias da empresa. 
Nesse sentido, o parecer do Departamento Jurídico do Iterpa de 1978 (Iterpa, 1978), elaborado como parte do processo de legitimação de 32 posses iniciado em 1976 por iniciativa da Jari, indica a existência de um "mapa geral das terras que [a empresa] se diz titular". Apesar de haver a confirmação de sua juntada ao referido processo (Iterpa, 1978, p. 3), o mapa está desaparecido.

Entre 1980 e 1986, esse processo de legitimação de posses deixou a competência do Iterpa para ficar a cargo do Grupo Executivo do Baixo Amazonas (Gebam), ${ }^{13}$ sem que tenha sido registrado qualquer encaminhamento. Ele foi reaberto no Iterpa apenas em 1996, dez anos após a extinção do Gebam, quando recebeu um novo número de protocolo e nova numeração de páginas. Ocorre que, em algum momento desse percurso, o mapa se perdeu e a follha onde ele estaria, a 454 da numeração antiga, não se encontra mais no processo.

Hoje, em meio ao conflito com comunidades e posseiros existente na área, o georreferenciamento virou "arma" na disputa e é tratado como um grande segredo. Nos processos em que a Jari requisita ao Iterpa reconhecimentos de domínio, por exemplo, há, em praticamente todos, indicações da contratação de serviços de georreferenciamento. Entretanto, nenhum resultado resta apensado ao processo. A única exceção é o processo de Santo Antônio da Cachoeira, que continha, em sua pasta, o relatório completo do georreferenciamento. ${ }^{14}$

\section{A unificação das matrículas}

Como mencionado acima, o latifúndio da Jari é formado por um mosaico de mais de cem imóveis. Cada um deles, registrado em matrícula própria nas respectivas circunscrições imobiliárias. E, em meio às intenções de legitimar as terras da Jari, está a tentativa, no fim da década de 1990, de unificar as matrículas, decorrente das fusões das transcrições e matrículas das terras das quais a empresa Jari Celulose, Papel e Embalagens S/A se anuncia proprietária. Essa unificação, obtida administrativamente por meio de requerimento ao oficial responsável pelo registro imobiliário, deu origem à matrícula n. 4.554, denominada Gleba Jari I, com 965.367,45 ha, lavrada às fls. 01 a 03 do Livro 2-S, do Registro de Imóveis de Monte Alegre, em 11 de agosto de 1998.

Com base nessa unificação dos títulos, a Jari Celulose elaborou e apresentou ao Instituto Brasileiro do Meio Ambiente e dos Recursos Naturais Renováveis (Ibama) um plano de manejo florestal a ser desenvolvido em 545 mil hectares pertencentes ao que seria a reserva legal do latifúndio, e que posteriormente passou a ser gerido pela Orsa Florestal, com base num contrato de comodato assinado entre as duas empresas.

A Promotoria Pública da Comarca do Município de Almeirim, porém, instaurou a Ação Civil Pública 02/2001, com o objetivo de investigar indícios de fraude no processo de unificação das matrículas. Em 27 de fevereiro de 2004, o Provimento n. 001/2004, da Corregedoria das Comarcas do Interior, "Declara o cancelamento e bloqueio das transcrições e matrículas,

13 O Gebam foi criado em 1980 (Decreto n. 84.516, de 28 de fevereiro de 1980, posteriormente modificado pelo Decreto n. 86.106, de 11 de junho de 1981), com foco bastante voltado ao Projeto Jari e seus problemas fundiários. Ele foi extinto em 1986, com o Decreto n. 92.678, de 19 de maio de 1986.

14 Também encontramos os relatórios de georreferenciamento de cinco aforamentos em seus respectivos pedidos de "Resgate administrativo". A única base espacial "oficial" a que tivemos acesso é o perímetro da suposta soma de todos os mais de cem imóveis dos quais a Jari se anuncia proprietária, obtido na base de dados declaratória do CAR. 
registros e averbações dos imóveis rurais abaixo arrolados, referentes ao Cartório de Registro de Imóveis e anexos da Comarca de Monte Alegre/PA", por ter como questionável a propriedade dos imóveis unificados.

De fato, a matrícula unificada (n. 4.554) era composta, além de títulos de suposta propriedade, de títulos de posse (que não configuram propriedade), e, até, de títulos de aforamentos, todos registrados como se de propriedade fossem. Analisando os registros citados no Provimento n. 001/2004 com base em informações contidas em outros documentos a respeito dessas áreas, temos:

- 42 registros com origem em títulos de posse, entre os quais quatro que, segundo relatório de procurador do Iterpa de 24 de abril de 1978, são terrenos de marinha; 15

- 27 títulos de propriedade;

- 18 prováveis aforamentos;

- 4 registros de desmembramentos de imóveis com título de posse;

- 21 transcrições sem identificação.

A batalha jurídica que se enredou a partir daí levou, em 25 de janeiro de 2006, o Conselho da Magistratura do Tribunal de Justiça do Estado do Pará a decidir por anular o cancelamento e determinar que os registros anteriormente cancelados devessem permanecer bloqueados.

Sobre essa prática - que não foi exclusividade da Jari - de se registrar como propriedades instrumentos tais como títulos de posses, vale lembrar que o Decreto n. 410/1891, primeira legislação paraense que regulamentou a questão fundiária, afinava-se à Lei de Terras, de 1850, ao vedar o apossamento de terras devolutas, instituindo o instrumento do título de posse para o exercício de tal controle. $\bigcirc$ fato, todavia, de essas posses serem tituladas ou legitimáveis, como dispunha, não significava domínio privado. Paulo Lamarão explica que, para que essa posse, como todas as demais, fosse considerada domínio, "era necessário, desde os meados do século passado [isto é, século XIX], que ela fosse legitimada” ([s.d.], p. 98, grifo nosso). Isso implicava, detalha o autor, que ela fosse demarcada, ocupada, e que seu detentor pagasse os emolumentos da tabela em vigor no momento da legitimação.

$\bigcirc$ caso de Santo Antônio da Cachoeira, entretanto, não se trata de um título de posse não legitimado, mas de um registro Torrens, um dos, senão o, mais sólido instituto de regulamentação da propriedade privada da terra. Entretanto, como veremos, neste caso, apesar da blindagem do Torrens, uma apropriação flagrantemente eivada de vícios e ilegalidades.

\section{O registro Torrens}

Inicialmente, importa apresentar a origem dessa modalidade de registro imobiliário, o também chamado Registro e Transmissão de Imóveis pelo Sistema Torrens e como seu uso por parte dos proprietários de terras passou por transformações após sua implementação em 1889. Torres $(2008,2012)$ ateve-se em depurada análise de registros Torrens emitidos justamente no estado do Pará. Este tópico segue e reproduz, em grande parte, seus estudos.

15 De acordo com o procurador, essas áreas estariam cadastradas no Serviço de Patrimônio da União, livro PA-12, sob os números de 2.847 a 2.851 (Tourinho Neto, 1978). 
Segundo Ligia Osório Silva (2008), o Serviço de Terras, órgão encarregado da gestão fundiária após a vigência da Lei de Terras, de 1850, defrontava-se com a dificuldade de discriminar as terras devolutas, ou seja, de separar o que seriam áreas públicas daquelas já alienadas e, portanto, de particulares. O Serviço confessava um limitado desenvolvimento na medição e na discriminação de terras devolutas, bem como nas ações de legitimação e revalidações de posses (Relatório da Inspetoria Geral de Terras e Colonização, 1889, ${ }^{16}$ p. 79 et seq. apud Silva, L., 2008, p. 248).

Até o período imediatamente anterior à Constituição Republicana, o Brasil carecia de qualquer sistema registral que lhe desse as mínimas condições de ter controle sobre seu imenso estoque de terras devolutas. Além disso, até a citada Constituição, que veio a disciplinar que aos Estados restaria o domínio das terras devolutas, isso era alvo de intensa contenda em que poderes centrais disputavam com oligarquias regionais a competência sobre a destinação dessas terras (Silva, L., 2008). Nesse bojo, e no sentido de disciplinar a questão ainda no Governo Provisório, é implementado o registro Torrens.

O instrumento vinha importado da Austrália, onde havia sido implementado em 1858, recebendo o nome de seu idealizador, o irlandês Robert Richard Torrens. No Brasil, é em 31 de maio de 1890, pelo Decreto n. 451-B, regulamentado pelo Decreto n. 955-A, de 5 de novembro de 1890, que entra em vigor o Registro e Transmissão de Imóveis pelo Sistema Torrens, com o intento de regularizar a situação fundiária do país. Rui Barbosa, na exposição de motivos do decreto que instituiu o sistema Torrens (Barbosa, 1891, p. 291-313), argumentava com fervor que o novo sistema se caracterizava pela segurança jurídica, ao permitir o expurgo de toda incerteza a respeito da cadeia de alienações, garantindo a continuidade do entrelaçamento dos sucessivos registros; valorização do título de propriedade, então depreciado pela interdependência das escrituras sucessivas de aquisição e transmissão; registro de todos os ônus reais incidentes sobre o imóvel.

Essencialmente, o Torrens preconizava a "depuração do título" antes do registro, ou seja, estipulava um período no qual qualquer interessado poderia questionar se o imóvel deveria mesmo ser transcrito em nome de quem o estaria pretendendo (Tupinambá Nascimento ${ }^{17}$ apud Jones, 1997, p. 150). Essa oposição, contudo, deveria necessariamente ocorrer no prazo previsto em lei, caso contrário presumia-se a preclusão do direito do opositor, "trazendo como consequência jurídica o silêncio para todo sempre a respeito desta oposição".

Após transcorridos os prazos tempestivos aos recursos que lhe possam ser opostos, o registro Torrens tem a sentença transitada em julgado e, a partir dela, a matrícula aberta no registro de imóveis não pode mais ser desconstituída. Assim, se o registro tradicional é passível de ser cancelado em decorrência de se evidenciarem fraudes ou até erros, ${ }^{18} \mathrm{O}$ mesmo não se

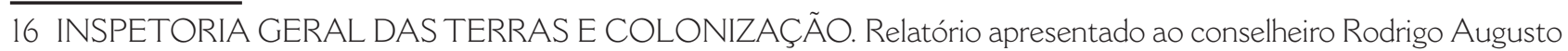
da Silva, ministro e secretário de Estado dos Negócios Estrangeiros e interino da Agricultura, Comércio e Obras Públicas, por Francisco de Barros Accioli de Vasconcellos, inspetor-geral, 1889.

17 NASCIMENTO, T. M. C. Introdução ao direito fundiário. Porto Alegre: Sérgio Antônio Fabris, 1985.

18 O registro ordinário, instituído pelo advento da Lei n. 3.071, de 1916, com sua entrada em vigor em 1917, confere apenas a presunção de propriedade: "No Brasil, um dos princípios que regem o registro de imóveis é o da força probante (fé pública) ou presunção. Os registros têm poder probante, eis que gozam de presunção juris tantum de veracidade. Tratase de uma presunção relativa, pois o adquirente do direito real é tido como titular da propriedade imóvel registrada até que se prove o contrário, conforme determina o artigo 1.245, § 2॰ do novel código [civil]" (Furlan, [s.d.]). Ver também, entre outros, Falcão (1995). 
passa com o Torrens, que, portanto, conferiria à propriedade privada um caráter absoluto. Dessa condição abre-se, na prática, uma oportunidade para a grilagem especializada, pois, como explica Jones, independentemente de se lhe provarem vícios de qualquer ordem, e até má fé, o Torrens permanece inabalado, e a propriedade não é, então, passível de questionamento.

Esta sempre foi uma grande porta aberta à grilagem especializada, fundada nas brechas abertas pela lei e que [...] aperfeiçoou-se, na medida em que os problemas fundiários se tornaram mais complexos e as terras, mais valorizadas. Essa modalidade "legal" e especializada de grilagem será cada vez mais desenvolvida com o suporte de verdadeiras assessorias jurídicas, tornando-se, em si mesma, um forte obstáculo aos processos de regularização fundiária e de reforma agrária (Jones, 1997, p. 151).

Torres (2008) registra o entusiasmo de juristas contemporâneos que vieram em defesa ao registro Torrens, tais como João Afonso Borges, que, em publicação de 1960, mostrava "a excelência desse processo, que deveria ser largamente aplicado nos levantamentos topográficos e nas ações de divisão e de demarcação, auxiliado e complementado pelos processos comuns e preconizados no Código de Processo" (Borges, 1976, ${ }^{19}$ p. 22 apud Torres, 2008, p. 237 et seq.). Avaliação semelhante à de Ismael Marinho Falcão, quando escreve, em 1995, que o registro Torrens é investido de "uma validade esplêndida na proteção do direito à propriedade" (Falcão, 1995,20 p. 111 apud Torres, 2008, p. 238) e, num tom salutar, garante que tal modalidade confere à propriedade privada um status intocável, garante à propriedade "o caráter de irrefragabilidade, vale dizer, contra a propriedade assim registrada a lei não admite possa contra ela haver qualquer ação de reivindicação. É a tranquilidade absoluta" (FALCÃO, 1995, p. 112 apud TORRES, 2008, p. 238).

Após a adoção, em 1917, do sistema de registro que, com algumas alterações, veio a derivar no que hoje está em vigor, o Torrens passa, portanto, a configurar um sistema paralelo. Mais que isso, o registro parece ter representado, ao longo do tempo, uma forma de blindar a grilagem de terras, como indica Torres (2008, 2012).

Um dos aspectos sociais mais flagrantemente indesejáveis do sistema foi sintetizado pelo agrarista Ismael Lima Falcão, justamente, ao fazer uma vigorosa defesa do instrumento: A propriedade, uma vez admitida a registro pelo sistema Torrens, estará perfeitamente saneada e esse saneamento perfeito da propriedade é, sem dúvida a grande e inabalável conquista desse tipo de registro, porque se trata de uma conquista do direito. Quantos proprietários rurais amargam, hoje, problemas sérios, quase irremovíveis, diante da política nefasta de determinados órgãos federais, que levantam dúvida sobre o domínio privado quarentenário antes da vigência do Código Civil, trazendo noites de insônia para empreendimentos de significativo valor econômico para a região onde se situam e para o próprio país, tão-somente para dar vazão a um sentimento discutível de proteção a determinadas castas, hoje

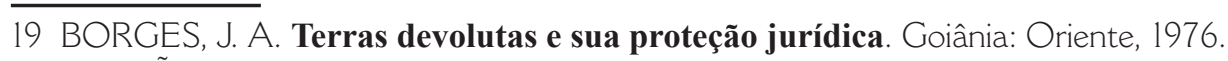

20 FALCÃO, I. L. Direito agrário brasileiro: doutrina, jurisprudência, prática. Bauru: Edipro, 1995. 
sem motivo nenhum para acobertar tutela. Verdadeiro crime contra a propriedade privada que não teria guarida se estivesse essa propriedade sob a proteção do Registro Torrens (Falcão, 1995, p. 113s. apud Torres, 2008, p. 267).

Entretanto, diversos documentos indicam que os casos de registro Torrens apresentados entre as pretensões da Jari (um total de seis) não podem ser considerados expressão de "saneamento perfeito da propriedade", como define Falcão. Segundo um parecer da própria Procuradoria Geral do Estado do Pará (PGE) que analisou, ao todo, 50 títulos supostamente representativos de domínio apresentados pela Jari (PGE, 2006), ${ }^{21}$ há vícios de origem no processo que teriam derivado nas sentenças judiciais e até suspeitas de inexistência das próprias sentenças que teriam determinado a abertura das matrículas Torrens, como veremos adiante, no caso do imóvel Santo Antônio da Cachoeira.

\section{Santo Antônio da Cachoeira e os outros cinco casos de registro Torrens}

Os seis imóveis apresentados pela Jari como de sua propriedade e que, de acordo com suas matrículas, foram registrados pelo sistema Torrens, ${ }^{22}$ têm um histórico muito semelhante: se originam de títulos de posse emitidos pela intendência municipal de Almeirim entre 1892 e 1909; não passaram pelo processo de legitimação de posse; e o suposto processo judicial que teria resultado no registro Torrens não foi localizado.

Uma vez que os títulos de posse não estavam legitimados, depura-se que o sistema de garantia da idoneidade da propriedade (Torrens) foi conferido ao que sequer propriedade era. Assim, por meio do registro Torrens, legitimou-se o domínio privado sobre área à revelia das normas estabelecidas para isso. $\bigcirc$ próprio modo como tal processo é citado nos documentos relativos aos imóveis que foram levados a registro imobiliário é sugestivo: a escritura pública que trata da venda das terras de José Júlio de Andrade para a empresa Jari Ltda., por exemplo, fala em "Título de Legitimação [...] expedido nos termos da 'Lei Torrens". ${ }^{23}$

Segundo análise da PGE (2006), quatro dos seis registros Torrens ${ }^{24}$ não são passíveis de serem reconhecidos como propriedade. Os outros dois, Santo Antônio da Cachoeira e Porto Salvo, entretanto, tiveram análise diferente.

O imóvel Santo Antônio da Cachoeira tem a segunda maior área pretendida pela Jari no Pará. De acordo com o título de propriedade, são 126.080 ha apenas no município de Almeirim, mais 295.741 ha se estendendo pelo estado do Amapá, além de 800 ha em ilhas, perfazendo, no todo, mais de 422 mil hectares.

Há ainda um enredo bastante obscuro no ato de destacamento deste imóvel do patrimônio público. Apesar de o relatório da PGE (2006) afirmar que não há, no Iterpa, registro do processo de origem desse imóvel, encontramos, seguindo as indicações da cadeia dominial

21 Esse relatório é assinado por um conjunto de procuradores do estado do Pará, mas o grupo que procedeu à análise dos documentos era composto também por representantes do Iterpa.

22 São eles: Ubintuba, Santa Margarida, Gavião, Samahuma, Santo Antônio da Cachoeira e Porto Salvo.

23 Cf. "Certidão da Escritura pública de venda e compra de diversas sortes de terras situadas no município de Almeirim, deste estado, entre as partes vendedores o Coronel José Júlio de Andrade e sua mulher, e compradora a empresa Jari Limitada como segue", livro 320, fls. 01 [24 dez. 1948]. 1. Ofício de Notas Cartório Chermont, Belém, 17 mar. 1989; p. 14.

24 Ubintuba, Santa Margarida, Gavião e Samahuma. 
apresentada pela Jari, às fls. 4v. do livro 01 de Registros de Posse de Almeirim, o registro da posse "Cachoeira", de 03 de junho de 1892, em nome de Martins E Irmão Ltda. Entretanto, o título que teria originado a matrícula apresenta a seguinte descrição: "Nome e situação do terreno: Cachoeira do Rio Jary e é conhecido por 'Cachoeira' - Município de Almeirim, Comarca de Gurupá - Área: tresentos hectares de extensão" (grifo nosso). Ou seja, teria menos de 1/1.400 avos do tamanho que viria a ter.

O aumento da superfície do imóvel pode, em parte, ser explicado: 45 anos após a emissão desse título de posse, Santo Antônio da Cachoeira, "ou simplesmente 'Cachoeira', foi descrito como incluindo outras sete posses que the teriam sido remembradas. Dessas sete, cinco ficariam à margem esquerda do rio Jari (hoje estado do Amapá) e duas à direita, além de cerca de uma dezena de ilhas. Neste momento, o imóvel é descrito com a área total de 422.622,6 ha. ${ }^{25}$

Porém, mesmo com o remembramento, nos parece inverossímil a inflação ocorrida, pois, se o limite legal para emissão de títulos de posse era de 4.356 ha, ${ }^{26}$ mesmo que as sete posses que foram unificadas ao imóvel Cachoeira tivessem o limite máximo, somariam pouco mais de 31 mil ha aos 300 ha iniciais, compondo uma extensão treze vezes menor do que o que está registrado hoje.

Nesse sentido, é sintomática a inexistência do procedimento de demarcação judicial do imóvel no processo que teria dado origem ao Torrens:

O que houve, quando muito, foi simples levantamento topográfico de diversas posses, com áreas incertas e/ou imprecisas, até porque, em momento algum o estado do Pará promoveu concessão de propriedade com a enorme dimensão de 422.622ha.50a.00ca. [...], como fato capaz de gerar qualquer presunção de domínio particular anterior àquela matrícula Torrens (Iterpa, 2005, p. 10).

Assim, parece claro que jamais poderia haver uma matrícula com tamanha extensão por conta do referido limite legal para emissão de títulos de posse.

Além das inconsistências referentes ao tamanho do imóvel, deve ser notada também a inexistência da legitimação dos títulos de posse que compõem o Torrens de Santo Antônio da Cachoeira. Não há qualquer registro de que o título de posse tenha sido levado a legitimação, para que, assim, pudesse constituir propriedade. Um simples título de posse de 300 ha (o título originário), segundo a PGE, seria passível, apenas, de originar o procedimento da legitimação de posse e não de dar origem a um procedimento de registro Torrens.

Em linha de demonstração da inexistência do registro Torrens de José Júlio de Andrade, verifica-se que é conditio sine qua non para dar início ao processo misto de registro Torrens a prova literal e legítima de propriedade privada, o qual inexiste conforme registro do Iterpa e é confessado pela própria Jari ao fazer referência a um título de posse (PGE, 2006, p. 42).

25 De acordo com o título de propriedade n. 18, Livro 1, Títulos de propriedade (Diversos municípios) - arquivo do Iterpa. 26 Art. 29, § $2^{\circ}$, da Lei n. 4.584, de 8 de outubro de 1975. 
Não menos grave é a ausência do processo pelo qual se teria emitido o Torrens. Apesar da existência da "matrícula Torrens" do imóvel, não existe, segundo a PGE, nenhum registro de que de fato tenha havido o processo de registro Torrens indispensável para que o próprio existisse (PGE, 2006, p. 41). Em outras palavras, esse tipo de registro necessariamente decorreria de sentença judicial e, se não houve essa sentença, não existiria o efeito do registro.

Já em 1931, não se sabia do paradeiro desse processo, tanto que José Júlio de Andrade solicitou, perante o Juízo da Comarca de Gurupá, a reconstituição dos autos do processo do registro Torrens supostamente iniciado pela empresa Martins E Irmão, cuja sentença teria sido emitida em 2 de agosto de 1902 e registrada no Livro Matriz da Comarca de Gurupá em 4 de abril de 1903. Porém, notam os procuradores da PGE que não existia na legislação da época uma hipótese legal que previsse a "restauração de autos de registro Torrens", "fato que demonstra que o imóvel em questão nunca esteve submetido a matrícula Torrens, vez que não existe e nunca existiu o livro especial de registro Torrens em Almeirim à época" (PGE, 2006, p. 42).

Em que pese todos esses vícios, parece que a frágil e improvável existência do registro Torrens surtiu efeito. Em 17 de setembro de 1937, conforme determinado por um ofício do Juiz de Direito da Comarca de Gurupá, o governador José Carneiro da Gama Malcher assina o título de propriedade em favor de José Júlio de Andrade. ${ }^{27}$

A própria emissão, nesses termos, do título de propriedade certifica a, nos termos da PGE, "flagrante irregularidade" do referido registro Torrens, e, portanto, da validade da matrícula do imóvel:

A simulação chega a um ponto de total desfaçatez que ao final do suposto "procedimento", determina-se ao Governador do Estado do Pará a expedição de título de propriedade em favor do Sr. José Julio de Andrade, quando o suposto título de propriedade deveria ter sido expedido a priori, como conditio sine qua non de legalidade e legitimação do processo de registro Torrens.

É bom salientar: o Governador do Estado do Pará à época somente expediu o título em virtude de uma sentença judicial inexistente supostamente proferida em uma simulação grosseira de procedimento de registro Torrens tomada com base em uma certidão do cartório de Almeirim ${ }^{[28]}$ que fazia referência a imóvel de área de 3.000 ha (três mil hectares) ${ }^{[29]}$ (PGE, 2006, p. 42).

Ou seja, o governador emitiu o título por força de um registro Torrens que só poderia existir a partir do referido título.

Como apontam os procuradores em outro parecer, o próprio processo de reconstrução dos autos também apresentaria uma série de problemas, pois seria impossível aferir, pelos documentos em questão, "a regularidade dos elos sucessórios referentes a esse imóvel no que diz respeito à transferência de direitos entre a empresa Martins E Irmãos Ltda. e o cidadão José Júlio de Andrade". Isso já denotaria, prosseguem os procuradores, "que existem várias lacunas

27 N. 18, Livro 1, Títulos de propriedade (Diversos municípios) - arquivo do Iterpa.

28 Às fls. 142 a 151 do Processo n. 96.327/2004(Iterpa), de reconhecimento de domínio do imóvel Santo Antônio da Cachoeira.

29 Acreditamos haver aí um erro de transcrição no relatório da PGE, pois o referido título de posse fala claramente em 300 ha, como vimos antes. 
nas transmissões dos supostos direitos que teriam legitimado o sr. José Júlio de Andrade a requerer a reconstituição do processo de registro Torrens, tido como originalmente concedido em favor da empresa Martins E Irmãos Ltda." (Iterpa, 2005, p. 8).

Apesar de a PGE ter identificado todos esses vícios, a própria procuradoria conclui que "somente são terras privadas a área do imóvel Santo Antônio da Cachoeira até o limite de 4.356 ha, sendo o excedente terras públicas" (PGE, 2006, p. 42).

Ora, causa estranheza que uma titulação que tenha sido adjetivada pela PGE como uma "simulação [que] chega a um ponto de total desfaçatez", como "simulação grosseira de procedimento de registro Torrens", seja contudo entendida pela própria PGE, no mesmo documento, como apta a conferir propriedade privada o limite máximo para alienação de terras à época da "simulação" (PGE, 2006, p. 42).

Os outros quatro registros Torrens apresentados pela Jari seriam ainda mais frágeis do que a "simulação grosseira" do imóvel Santo Antônio da Cachoeira. A diferença entre esse e os quatro citados anteriormente, que, no entanto, foram considerados no parecer da PGE integralmente terras públicas, é que Santo Antônio da Cachoeira, ainda que tenha tido o Torrens emitido antes da legitimação do título de posse - ou seja, sem que houvesse a propriedade -, em decorrência da suposta sentença judicial que determinou a abertura da matrícula Torrens, foi emitido (extemporaneamente) o título de propriedade pelo estado do Pará, pelo próprio governador. Esse título, mesmo que oriundo de processo eivado de vícios, levou a PGE a recomendar o reconhecimento, ainda que em parte, de propriedade privada, coisa que não o fez para os outros quatro.

O sexto e último caso de registro Torrens entre as pretensões da Jari, o imóvel Porto Salvo, é ainda mais curioso. Para essa matrícula de 6.848 ha, a PGE também recomenda o reconhecimento de 4.356 ha como propriedade privada alegando que ele, à semelhança de Santo Antônio da Cachoeira, também possui um título de propriedade. Contudo, a localização desse título citada no relatório da PGE é, na verdade, a do título de propriedade de Santo Antônio da Cachoeira. Por mais que tenhamos procurado, não localizamos tal título para Porto Salvo; ele não é sequer citado em nenhum dos documentos consultados ao longo da pesquisa que realizamos nos arquivos do Iterpa. A menos que esse documento venha a ser localizado, acreditamos ter havido uma confusão que levou a uma avaliação errônea da PGE.

Sobre Porto Salvo, é preciso ainda dizer que, em 31 de julho de 1989, ele foi unificado com o imóvel contíguo Estirão do Caracuru e incorporado à matrícula desse, de $n$. 4.149, no Registro de Imóveis de Monte Alegre. Suas áreas foram somadas formando um imóvel de 7.864 ha. Em 2002, o imóvel Estirão do Caracuru Porto Salvo foi objeto de hipoteca, tendo, posteriormente, seu registro transferido para o Registro de Imóveis de Almeirim, hoje matrícula n. 272, fls. 01, livro 2-B. É particularmente importante para a Jari a situação regular dessa matrícula pois é a área onde se localiza a Vila Munguba, onde está instalada a fábrica de celulose. ${ }^{30}$

30 Vale notar que o imóvel Estirão do Caracuru Porto Salvo não está incluído no já referido bloqueio das matrículas, obtido por meio da Ação Civil Pública n. 02/2001, proposta pela Promotoria Pública da Comarca do Município de Almeirim com o objetivo de investigar indícios de fraude no processo de unificação das matrículas. 


\section{Considerações finais}

A atual procuradora-chefe da Procuradoria Jurídica do Iterpa, Tátilla Passos Brito, corrobora a avaliação da PGE (comunicação pessoal em 30 jan. 2015). Para ela, apesar de todos os vícios e ilegalidades apontados no processo que originou o registro Torrens de Santo Antônio da Cachoeira, até hoje nenhuma providência jurídica foi tomada para sua anulação e não caberia ao Iterpa, por via administrativa, questioná-lo, ainda que se trate de um título fraudado que levou à apropriação ilegal de 126 mil ha de terras do próprio Iterpa. De acordo com suas palavras, o registro foi emitido por instância competente, e o órgão não pode ignorá-lo, o que procede; entretanto, fica a dúvida sobre a razão que leva o Iterpa a não recorrer a instâncias igualmente competentes para reverter a seu patrimônio as terras ilegalmente tituladas.

E assim permanecem as coisas: cristalizadas. O status quo vem em franco benefício do latifúndio e em prejuízo de camponeses que lá vivem, a quem essas terras públicas deveriam ser destinadas.

Independentemente das garantias constitucionais à sentença transitada em julgado, há precedentes, no Pará mesmo, de registros Torrens questionados e com decisões liminares contrárias à grilagem (Torres, 2008). Acrescendo a isso a lembrança da imprescritibilidade das ações de ressarcimento sobre crimes contra o patrimônio público, ${ }^{31}$ entendemos como questionável a inação do Iterpa.

Como procuramos mostrar, a apropriação ilegal de terras públicas pela Jari não se limita a esses seis casos de registros Torrens. $\bigcirc$ latifúndio ao qual a empresa se arroga, cuja pretensão atinge hoje cerca de 916 mil ha, é um mosaico composto de mais de cem imóveis com diferentes tipos de títulos. Entre os documentos apresentados pela empresa, são flagrantes as incongruências, tanto que nem ela própria reivindica hoje a totalidade da área descrita nesses títulos. A análise desses títulos indica que cerca de 95\% das áreas neles descritas existem apenas no papel (ou seja, não podem ser fisicamente localizadas) ou são terras públicas. Os títulos que não apresentam irregularidades são de um total de aproximadamente 156 mil ha, o que já constituiria um imenso latifúndio.

Entre os diferentes tipos de títulos apresentados, destacamos seis registros Torrens, um tipo de matrícula que torna inquestionável a propriedade da terra e que, justamente por isso, tem sido usado na tentativa de consolidar irrevogavelmente a apropriação indevida de terras públicas, configurando um tipo específico de grilagem especializada. No caso das pretensões da Jari, com base em processos e documentos existentes no Iterpa e em análises do próprio estado do Pará, esperamos ter demonstrado a fragilidade desses registros.

Diante dos casos apresentados, parece-nos muitas vezes injustificável a postura da PGE, e também do Iterpa, no sentido de recomendar o reconhecimento, ainda que em parte, de alguns desses títulos. De todo modo, independentemente das conclusões e recomendações desses órgãos, a demora de medidas efetivas tem permitido, na prática, a apropriação de terras públicas.

Conforme já demonstrado (Camargo, 2015), há quase 40 anos e em sucessivos governos, o Estado aquiesce com esse quadro, seja por omissão, seja por atos objetivos como, por exemplo, o que permite a exploração madeireira em terras públicas que podem estar ocupadas por comunidades camponesas.

31 Art. 37, § 5 da Constituição Federal. 
Mas palavras de James Holston (1993), "como podemos pensar o direito se o sistema jurídico não objetiva resolver os conflitos, se é um meio de perpetuar e obscurecer as disputas em vez de resolvê-las?". O que se pode esperar como solução para uma das maiores grilagens do planeta, se justamente essa condição parece ser seu maior trunfo de empoderamento político para assim se manter?

\section{Referências}

ARAÚJO, F. C. CAR para "inglês ver". Instituto Socioambiental, 12 maio 2014a. Disponível em: <http://www.socioambiental.org/pt-br/blog/blog-do-ppds/car-para-ingles-ver>. Acesso em: 30 maio 2014.

. Cadastro Ambiental Rural: "falta prioridade política para a gestão ambiental no campo". Entrevista. Instituto Humanitas Unisinos, 27 maio 2014b. Disponível em: $<$ http://www.ihu.unisinos.br/entrevistas/cadastro-ambiental-rural-falta-prioridade-politica-para-a-gestao-ambiental-no-campo-entrevista-especial-com-flavia-camargo-de-araujo/531707-cadastro-ambiental-rural-falta-prioridade-politica-para-a-gestao-ambiental-no-campo-entrevista-especial-com-flavia-camargo-de-araujo>. Acesso em: 30 maio 2014.

BARBOSA, R. Exposição de motivos ao Decreto n. 451-B, de 1890. In: Obras Completas, v. XVIII, t. II. Rio de Janeiro: Ministério da Saúde e Educação, 1891. p. 291-313. Disponível em: <http://www.casaruibarbosa.gov.br/rbonline/obrasCompletas.htm>. Acesso em: 3 abr. 2015.

BORGES, J. A. O registro Torrens no direito brasileiro. São Paulo: Saraiva, 1960.

BRASIL. Presidência da República. Lei n. 12.651, de 25 de maio de 2012. Dispõe sobre a proteção da vegetação nativa; altera as Leis n. 6.938, de 31 de agosto de 1981, 9.393, de 19 de dezembro de 1996, e 11.428, de 22 de dezembro de 2006; revoga as Leis n. 4.771, de 15 de setembro de 1965, e 7.754, de 14 de abril de 1989, e a Medida Provisória no 2.166-67, de 24 de agosto de 2001; e dá outras providências. Disponível em: <http:// www.car.gov.br/leis/LEI12651.pdf>. Acesso em: 10 jun. 2013.

. Instituto Nacional de Colonização e Reforma Agrária. Procuradoria Federal Especializada junto ao Incra. Lei n. 8.629/93 comentada por procuradores federais: uma contribuição da PFE/Incra para o fortalecimento da reforma agrária e do direito agrário autônomo. Brasília: Incra, 2011.

- Presidência da República. Lei n. 10.406, de 10 de janeiro de 2002. Institui o Código Civil. Disponível em: <http://www.planalto.gov.br/ccivil_03/leis/2002/110406.htm>. Acesso em: 20 abr. 2015.

- Presidência da República. Constituição da República Federativa do Brasil de 1988.

Disponível em: <http://www.planalto.gov.br/ccivil_03/constituicao/constituicaocompilado.htm>. Acesso em: 20 abr. 2015. 
Presidência da República. Lei n. 4.504, de 30 de novembro de 1964. Dispõe sobre o Estatuto da Terra, e dá outras providências. Disponível em: <http://www.planalto.gov. br/CCIVIL_03/leis/L4504.htm>. Acesso em: 3 mar. 2015.

Presidência da República. Lei n. 3.071, de 10 de janeiro de 1916. Código Civil dos

Estados Unidos do Brasil. Disponível em: <http://www.planalto.gov.br/ccivil_03/leis/ L3071.htm>. Acesso em: 20 abr. 2015.

Lei n. 601, de 18 de setembro de 1850. Disponível em: <http://www.planalto.gov.br/ ccivil_03/Leis/L0601-1850.htm>. Acesso em: 8 dez. 2012.

BUENO, R. A negociata da nacionalização do Jari. In: MOREL, E. Amazônia saqueada. 3. ed. rev. e ampl. São Paulo: Global, 1989.

CAMARGO, M. L. G. O latifúndio do Projeto Jari e a propriedade da terra na Amazônia brasileira. 2015. Dissertação (Mestrado em Geografia Humana) - Faculdade de Filosofia, Letras e Ciências Humanas, Universidade de São Paulo, São Paulo, 2015.

CARNEIRO, G. Jari: uma responsabilidade brasileira. São Paulo: Lisa, 1988.

CAVAlCANTI, K.; FERRAZ, S. Vende-se por 1 dólar. Veja, São Paulo: Abril, 7 jul. 1999. Disponível em: <http://veja.abril.com.br/070799/p_074.html>. Acesso em: 29 set. 2011.

CHACPE, J. F. Do conceito de imóvel rural, [2012] Disponível em: <http://www.incra.gov. br/index.php/procuradoria/artigos-e-doutrinas/file/1093-do-conceito-de-imovel-rural-por-juliana-fernandes-chacpe>. Acesso em: 25 mar. 2014.

ERPEN, D. A. O registro Torrens e o sistema imobiliário atual. Revista de Direito Imobiliário, São Paulo: Irib, n. 19-20, p. 60-72, jan./dez. 1987.

FALCÃO, I. L. Direito agrário brasileiro: doutrina, jurisprudência, prática. Bauru: Edipro, 1995.

FURLAN, J. C. Quem registra não é dono. Disponível em: <http://www.exacta.cnt.br/ news/ se-mana/04092003.html>. Acesso em: 20 mar. 2006.

GI SANTARÉM. Madeireira tem atividades suspensas por fraudes em manejo florestal no PA. G1, Santarém, 9 jul. 2015. Disponível em: <http://gl.globo.com/pa/santarem-regiao/noticia/2015/07/madeireira-tem-atividades-suspensas-por-fraudes-em-manejo-florestal-no-pa.html>. Acesso em: 10 jul. 2015.

GARRIDO FILHA, I. B. M. O Projeto Jari e os capitais estrangeiros na Amazônia. Petrópolis: Vozes, 1980.

HOLSTON, J. Legalizando o ilegal: propriedade e usurpação no Brasil. Revista Brasileira de Ciências Sociais, São Paulo, v. 8, n. 21, fev. 1993. Disponível em: <http://www. anpocs.org.br/portal/publicacoes/rbcs_00_21/rbcs21_07.htm>. Acesso em: 29 jun. 2015. 
IANNI, O. Ditadura e agricultura. Rio de Janeiro: Civilização Brasileira, 1986.

INCRA. Procuradoria Federal Especializada junto ao Incra. Lei n. 8.629/1993 comentada por procuradores federais: uma contribuição da PFE/Incra para o fortalecimento da reforma agrária e do direito agrário autônomo. Brasilia: Incra, 2011.

ITERPA. Processo n. 2005/169.308. Relatório dos procuradores Carlos Lamarão Correa e Ibraim J. das Mercês Rocha à presidência do Iterpa. Belém, 2005

Parecer do Departamento Jurídico, de 10 de julho de 1978, no âmbito do Processo n. 05.562/1976, assunto: solicitação de legitimação de posse; interessado: Jari Florestal e Agropecuária Ltda. Belém, 1978.

JONES, A. S. A política fundiária do regime militar: legitimação privilegiada e grilagem especializada (do Instituto de Sesmaria ao Estatuto da Terra). Tese (Doutorado em Sociologia) - Faculdade de Filosofia, Letras e Ciências Humanas, Universidade de São Paulo, São Paulo, 1997.

LAMARÃO, P. Comentários à legislação de terras do estado: outros ensaios. Belém: Grafisa, [s.d.].

LINS, C. Jari: 70 anos de história. Almeirim: Dataforma/Prefeitura Municipal de Almeirim, 1991.

MMA. MINISTÉRIO DO MEIO AMBIENTE. Instrução Normativa n. 2, de 6 de maio de 2014. Dispõe sobre os procedimentos para a integração, execução e compatibilização do Sistema de Cadastro Ambiental Rural-SICAR e define os procedimentos gerais do Cadastro Ambiental Rural-CAR.

MOREIRA, E. C. P. Conflitos socioambientais: terra, água e floresta. In: CONGRESSO DE GEOGRAFIA AGRÁRIA AMAZÔNICA: dinâmicas e conflitos territoriais no espaço agrário amazônico, 1., 6-9 out. 2014, Belém. Disponível em: <https://www.youtube. com/watch?v=QfBgQSAHNFI\#t=319>. Acesso em: 3 mar. 2015.

MOREL, E. Amazônia saqueada. 3. ed. rev. e ampl. São Paulo: Global, 1989.

PONTES DE MIRANDA. I. Direito das coisas - propriedade: aquisição da propriedade imobiliária. 2. ed. Campinas: Bookseller, 2001.

OLIVEIRA, A. U. Amazônia: monopólio, expropriação e conflitos. Campinas: Papirus, 1995.

PARÁ. Assembleia Legislativa. Constituição do Estado do Pará. Texto promulgado em 5 de outubro de 1989 e atualizado até a Emenda Constitucional n. 53, de 21 de março de 2012. Disponível em: <http://www2.senado.leg.br/bdsf/item/id/243099>. Acesso em: 3 mar. 2015.

Poder Judiciário. Corregedoria de Justiça das Comarcas do Interior. Provimento n. 013/2006-CJCl. Dispõe sobre a averbação de bloqueio de matrículas de áreas rurais nos Cartórios do Registro de Imóveis nas Comarcas do Interior e dá outras providências. Diário da Justiça, n. 3672, 23 jun. 2006. 
Assembleia Legislativa. Lei estadual n. 913, de 4 de dezembro de 1954. Dispõe sobre a colonização e aquisição de terras devolutas do Estado e a extração dos seus produtos nativos e dá providências correlatas. Belém, 1954.

PGE. Procuradoria Geral do Estado do Pará. Relatório com as conclusões dos Procuradores do Estado, referentes à análise dos documentos realizada pelo grupo de trabalho instituído pela portaria n. 001/06-PGE-GAB-ITERPA, de 18 de julho de 2006. Diário Oficial do Estado, Belém, set. 2006, n. 30.731.

PINTO, L. F. Grilagem: R\$ 35 bilhões em causa. Adital, Fortaleza, 16 abr. 2013. Disponível em: $<$ http://www.adital.com.br/site/noticia_imp.asp?lang=PTEimg=NEcod=74730>. Acesso em: 20 ago. 2015.

Jari: toda a verdade sobre o projeto de Ludwig. São Paulo: Marco Zero, 1986.

SANTOS, D. Sesmarias, terras devolutas e registro paroquial. Revista de Direito Agrário, Brasília: Incra, v. 10, 1983.

SAUTCHUK, J.; CARVAlHO, H. M.; GUSMÃO, S. B. Projeto Jari: a invasão americana. São Paulo: Brasil Debates, 1981.

SILVA, J. G. Princípios constitucionais básicos da Reforma Agrária. Revista Reforma Agrária, Campinas, ano 16, n. 1, abr./jul. 1986, p. 28 et seq. Disponível em: <http://www. docvirt.com/docreader.net/DocReader.aspx?bib=HEMEROLTEPagFis=9670>. Acesso em: 8 abr. 2015.

SILVA, L. O. Terras devolutas e latifúndio: efeitos da Lei de 1850. 2. ed. Campinas: Unicamp, 2008.

SILVEIRA, M. Ludwig, o imperador do Jari. Rio de Janeiro: Civilização Brasileira, 1980.

STEFANINI, L. L. A beiradeira e o grilador: ocupação e conflito do oeste do Pará. Dissertação (Mestrado em Geografia Humana) - Faculdade de Filosofia, Letras e Ciências Humanas, Universidade de São Paulo, São Paulo, 2008.

A propriedade no direito agrário. São Paulo: Ed. Revista dos Tribunais, 1978.

TORRES, M. Terra privada, vida devoluta: ordenamento fundiário e destinação de terras públicas no oeste do Pará. Tese (Doutorado em Geografia Humana) - Faculdade de Filosofia, Letras e Ciências Humanas, Universidade de São Paulo, São Paulo, 2012.

A beiradeira e o grilador: ocupação e conflito do oeste do Pará. Dissertação (Mestrado em Geografia Humana) - Faculdade de Filosofia, Letras e Ciências Humanas, Universidade de São Paulo, São Paulo, 2008.

TOURINHONETO, A. C. Relatório de viagem. Belém, 24 abr. 1978. Processon. 78.180/1996. Iterpa [antigo 05.562/1976].

TRECCANI, G. D. Violência e grilagem: instrumentos de aquisição da propriedade da terra no Pará. Belém: UFPA/Iterpa, 2001. 